\title{
Motor development evaluated by Test of Infant Motor Performance: comparison between preterm and full-term infants
}

\section{Desenvolvimento motor avaliado pelo Test of Infant Motor Performance: comparação entre lactentes pré-termo e a termo}

Carmen L. N. Guimarães', Cyda M. Reinaux², Ana C. G. Botelho³, Geisy M. S. Lima ${ }^{4}$, José E. Cabral Filho ${ }^{5}$

\begin{abstract}
Objectives: To compare the motor development of preterm infants whose gestational age had been corrected to 38-40 weeks with full term newborns using the Test of Infant Motor Performance (TIMP). Methods: The cross-sectional study compared preterm infants (PT group), with a gestational age at birth of 28-33 weeks, at an equivalent age to full term newborns (FT group), who were assessed up to 48 hours after birth. The assessments were performed between December 2008 and April 2009 in a hospital nationally recognized for premature infant care in the city of Recife, PE, Brazil. The sample consisted of 92 infants, 46 in each group. The test was administered at age 38-40 weeks (or equivalent age in the PT group). Results: In the 46 preterm infants studied, $26.1 \%$ were classified as atypical, while in the FT group 100\% were classified as typical $(p<0.001)$. Moreover, there was a significant difference in average raw TIMP score between the two groups, with the PT group being lower $(p<0.001)$. Conclusions: According to TIMP performance, prematurity seems to be associated with impaired motor development.
\end{abstract}

Keywords: motor skills; newborn; premature; early diagnosis; neuropsychological tests/standards; rehabilitation.

\section{Resumo}

Objetivos: Comparar, por meio do Test of Infant Motor Performance (TIMP), o desenvolvimento motor de lactentes nascidos pré-termo que estavam com idade gestacional corrigida de 38 a 40 semanas com o de recém-nascidos a termo. Métodos: Estudo de desenho transversal em que se comparou o desempenho motor de lactentes pré-termo (grupo RNPT), com idade gestacional no parto de 28 a 33 semanas, avaliados na idade equivalente ao termo, com o de recém-nascidos a termo (grupo RNT), avaliados em até 48 horas de vida, por meio do TIMP. A coleta dos dados foi realizada no período de dezembro de 2008 a abril de 2009, num hospital de referência para assistência a prematuros na cidade de Recife, PE, Brasil. A amostra foi constituída de 92 lactentes, 46 para cada grupo. O teste foi aplicado na idade de 38 a 40 semanas de idade gestacional (corrigida, no caso dos lactentes nascidos pré-termo). Resultados: Dos 46 lactentes pré-termo avaliados, 26,1\% foram classificados como atípicos, enquanto $100 \%$ dos recém-nascidos a termo foram classificados como típicos $(p<0,001)$. Além disso, houve diferença significativa na média do escore bruto do teste nos dois grupos, sendo a média do grupo RNPT menor $(p<0,001)$. Conclusões: A prematuridade parece estar associada a prejuízo no desenvolvimento motor, avaliado pelo TIMP.

Palavras-chave: destreza motora; recém-nascido; prematuro; diagnóstico precoce; testes neuropsicológicos/normas; reabilitação.

Received: 06/29/2010 - Revised: 12/08/2010 - Accepted: 04/26/2011

\footnotetext{
Outpatient Clinic of the Egress of the Kangaroo Method, Instituto de Medicina Integral Prof. Fernando Figueira (IMIP), Recife, PE, Brazil 'Laboratory of Cardiopulmonary Physical Therapy, Universidade Federal de Pernambuco (UFPE), Recife, PE, Brazil

${ }^{3}$ Center of Rehabilitation, IMIP

${ }^{4}$ Coordination of the Neonatal Unit, IMIP

${ }^{5}$ Postgraduate Program of Maternal-Child Health, IMIP

Correspondence to: Carmen Lúcia Neves Guimarães, Rua Nilson Sabino Pinho, 368, apto 301, Jardim Atlântico, CEP 53050-010, Olinda, PE, Brasil, e-mail: calunegui@hotmail.com
} 


\section{Introduction $\because \therefore$.}

Technological advances in the care of preterm newborns (PTN) have contributed to reduced mortality levels in this population ${ }^{1-3}$. Nevertheless, the number of preterm infants presenting alterations in neuromotor function, hearing, language and cognitive development has increased ${ }^{3-5}$. Greater understanding of these alterations is extremely important, since they can have psychomotor effects and impair learning when these children reach school age ${ }^{6,7}$. Early diagnosis of these alterations is necessary so that motor interventions can be initiated as early as possible ${ }^{4}$.

The uterine environment in the third trimester offers a series of sensory stimuli for the vestibular, tactile, kinesthetic and auditory systems, producing beneficial effects on fetal development ${ }^{8}$. However, when premature childbirth occurs, newborns (NB) submitted to a neonatal intensive care unit (NICU) may be exposed to environmental stimuli such as a high level of background noise, a lack of daily lightdark cycle and excessive handling, which can be harmful to the NB because of his/her immaturity ${ }^{8,9}$.

In addition, the PTN presents hypotonia and central nervous system (CNS) immaturity which, associated with the excessively large incubator space and the action of gravity, cause extended posture and difficulty executing flexion movements ${ }^{8.9}$. These phenomena occur during a period of enhanced cerebral organization and high cephalic plasticity, making the CNS highly vulnerable to environmental influence ${ }^{9,10}$. The musculoskeletal system of the PTN is also very vulnerable to the NICU environment and the baby's extended posture predisposes him/her to muscular retractions, which can cause further delays in motor development ${ }^{11,12}$.

Investigations on muscular tonus in PTN have been conducted with techniques involving reflex and behavioral responses. The results of these studies have indicated that preterm infants present abnormal trunk muscular tone, which induces developmental delays ${ }^{12-14}$.

On the other hand, the high plasticity of PTN nervous and musculoskeletal systems makes them sensitive to beneficial or harmful stimuli. Early motor intervention can facilitate motor development and help minimize the harmful effects of the NICU environment ${ }^{8,10,11}$. The use of standardized tests is necessary for adequate diagnosis of motor performance as well as adequate early intervention ${ }^{10,15,16}$. Among the specific tests used to assess the motor development of babies, the Test of Infant Motor Performance (TIMP) was developed for early identification of neuromotor disturbance and to assess the efficacy of physical and occupational therapy in clinical practice ${ }^{17,18}$. It is a standardized test for assessing babies from 34 weeks postconceptional age to four months past term equivalent age. It considers the influences of the infant's neurological maturation, the environment, the force of gravity and posture on motor development. The test is composed of two parts, one of observed items in which spontaneous movements are recorded and the other of elicited items in which the motor response is recorded during different movements and postures, as well as the infant's attention to visual and auditory stimuli ${ }^{17-19}$.

There are other instruments ${ }^{20-23}$ for assessing the development of newborns, but they are designed for infants with over 40 weeks of corrected gestational age or those at least four months of age. Although studies ${ }^{10,24-27}$ assessing the motor development of preterm infants below this age group have been conducted, few have investigated motor skills in detail with the TIMP ${ }^{26,27}$, and the latter did not study preterm and full term infants comparatively.

Therefore, the purpose of the present study was to compare the motor development of preterm newborns with that of full-term newborns (FTN) using the TIMP.

\section{Methods : :}

This study was developed at the Instituto de Medicina Integral Prof. Fernando Figueira (IMIP), in Recife, PE, Brazil, which is a nationally recognized hospital for low birthweight NB, where 5000 babies are born annually, $29.5 \%$ of whom are premature ${ }^{28}$. Data collection was carried out between December 2008 and April 2009. This is a cross-sectional design study, in which the TIMP was used to compare the motor development of two groups of newborns; one group of preterm infants and another of full-term infants. This study considered the raw test score and the classification as either typical or atypical according to the z-score, as recommended in the test handbook. The first group (PTN) consisted of preterm infants born at the IMIP with gestational ages between 28 and 33 weeks and whose age was equivalent to full term (38 to 40 weeks) when the test was administered. Within this group, a subgroup of PTN was studied that had suffered clinical intercurrences (infections, persistence of the arterial duct and intracranial hemorrhage grade I or II). The second group (FTN) consisted of full term newborns born at the IMIP whose gestational age was between 38 and 40 weeks. The PTN group was selected through analysis of the medical records of NB hospitalized at the IMIP neonatal unit and the FTN group was selected from the IMIP's rooming-in unit.

Newborns who were in the NICU on their evaluation day were excluded, as were those whose medical records included any of the following occurrences: an Apgar score 
below 7 in the fifth minute, the presence of congenital malformations or a diagnosis of congenital infection, a genetic syndrome (confirmed or suspected), an image diagnosis of intracranial hemorrhage grade III or IV and/or periventricular leukomalacia and/or cysts or intracranial abscesses, a diagnosis of bronchodysplasia, infections of the nervous system or submission to any surgical procedure, being small for gestational age (birthweight below the $10^{\text {th }}$ percentile) or having a mother addicted to alcohol or illicit drugs.

The sample size for each group was determined with the following formula: $N=2\left(Z_{\alpha}+Z_{\beta}\right)^{2} \cdot \sigma^{2} / d^{2}$, where $N$ is the sample size, $Z_{\alpha}=1.96(\alpha=0.05), Z_{\beta}=0.84(\beta=0.80), \sigma=14$, according to Campbell et al. ${ }^{27}$, and the estimation of the minimal difference between the mean of the raw score of the PTN and FTN groups was $8(\mathrm{~d}=8)$ according to the pilot study. The sample size determined was 48 newborns for each group. This number was increased by $10 \%$ to compensate for possible losses, resulting in a total of 53 infants for each group.

Data collection related to the NB's maternal, biological and clinical variables was carried out on the same day that the TIMP was administered and was transcribed to a specially-created form. Maternal variables included age, education level, family income, type of childbirth and number of prenatal consultations. NB biological and clinical variables included gender, gestational age at childbirth, corrected gestational age on the day of assessment, birthweight, Apgar score in the first and fifth minutes, the presence of clinical intercurrences (infections, persistence of the arterial duct, intracranial hemorrhage levels I or II), length of stay in the NICU and newborn intermediate care unit (NIC) and in kangaroo care (stay at the Kangaroo Care Unit of the hospital), time since discharge (time elapsed between infant discharge and TIMP assessment), raw TIMP score and classification of motor development (typical or atypical) according to the TIMP.

The TIMP was administered by one of the authors (CLNG or ACGB) who had been trained in handling at-risk newborns as well as the in use of the scale by the test training program. The test formula was filled out at the time the test was applied. Each test session was filmed, recorded to DVD and subsequently analyzed by the research team, from which the test result was defined by consensus.

Standardized material and protocol were used to administer the TIMP ${ }^{29}$. To obtain a reliable response, the infant should be in states 3, 4 or 5 described in the Brazelton Neonatal Behavioral Assessment Scale (somnolence, alert inactive and alert active, respectively), dressed only in diapers and lying on firm surface (rubber mat) at room temperature (25-29 $\left.{ }^{\circ} \mathrm{C}\right)$. The test began with the observational items; the researcher was allowed to visually or verbally stimulate the infant to keep him/her in the above mentioned states of consciousness in order to facilitate observation of spontaneous movement. This part was scored as 1 for the presence of motor response and 0 for the absence of response. The elicited items were then evaluated, with up to three repetitions of each item. The best response was chosen for scoring purposes. In this part each item was graded according to the skill level presented ${ }^{29}$.

The quantification of the raw score was based on the sum of the values obtained in each of the items ${ }^{29}$. Development was classified according to the Z-score (from the normalization of the raw score) as either typical (Z-score $\geq-0.5$ ) or atypical (Z-score $<-0.5)^{30}$.

This investigation was approved by the Research Ethics Committee of the IMIP, under protocol 1312-08. The individuals responsible for the newborns gave free and informed consent for their participation in the study and signed the consent form.

\section{Statistical analysis}

Prior to statistical analysis, the normality of distribution (Kolmogorov-Smirnov test) and homogeneity of variance between groups (Levene test) were verified. The analyses took these sampling characteristics into consideration. Student's $t$-test was used to compare the mean raw score values between groups. The Mann-Whitney U-test was used to compare the medians (Apgar scores). For correlations between the clinical variables and the raw TIMP score, Pearson's Correlation was used if the variables were normally distributed (birthweight, length of stay at NICU and in kangaroo care) and Spearman's Correlation if they were non-normally distributed (gestational age and length of discharge). To compare the frequency values (typical or atypical) between the groups, the Fisher's Exact Test was used since the data did not match the criteria for the Chi-square test. The alpha value was 0.05 to reject the null hypothesis.

\section{Results $: \because$.}

Of the 106 newborns initially selected (55 PTN and 51 FTN), nine of the preterm babies that had already been discharged from the hospital did not return for the TIMP assessment. Five full-term babies did not complete the assessment since they moved into Brazelton state 6 (crying) during the test. Thus, the final sample was 92 newborns, with 46 in each group. 
Of the maternal characteristics (Table 1) - age group, education level, family income, type of childbirth and number of prenatal consultations - only the final one diverged statistically ( $\mathrm{p}=0.024)$. Regarding the age of the newborns, it was verified that the mean gestational age at birth was 31.1 weeks $(\mathrm{SD}=1.5)$ in the PTN group and 38.6 weeks $(\mathrm{SD}=0.5)$ in the FTN group. The mean birthweight was $1424 \mathrm{~g}(\mathrm{~S}=321.1)$ in the PTN group and $3158 \mathrm{~g}(\mathrm{SD}=565.4)$ in FTN. Regarding gender, $52.1 \%$ of the PTN group were male and $50 \%$ of the FTN group were male. The median Apgar Score at the fifth minute was 9.0 (min. 7 and max. 10) in the PTN group and 9.0 (min. 8 and max. 10) in the FTN group, with no statistical difference between them. In the PTN group, a subgroup of 18 newborns presented one or more intercurrences: 15 had slight infectious affections (and one also had a grade I or II intracranial hemorrhage) and three had persistence of the arterial duct (and one also had a grade I or II intracranial hemorrhage).

Regarding the raw score (Table 2), PTN performance was significantly lower $(14.5 \%)$ than FTN, with mean scores of $58(\mathrm{SD}=7.9)$ and $67.9(\mathrm{SD}=5.3)$, respectively $(\mathrm{p}<0,001)$. Regarding motor development (Table 2), 12 of the 46 preterm newborns $(26.1 \%)$ were classified as atypical, while $100 \%$ of the FTN were classified as typical $(\mathrm{p}<0.001)$.

Regarding the presence of intercurrences (Table 3) in the PTN group, there were no statistical differences in either mean raw score $(p=0.246)$ or motor development classification $(p=0.308)$.

According to the correlation tests, no association was found between the raw score and the variables birthweight, gestational age, length of stay in the NICU and NIC, length of stay in the Kangaroo Unit and length after discharge for PTN or between birthweight and gestational age for FTN.

Table 1. Maternal variables of preterm infants and fullterm newborn evaluated by Test of Infant Motor Performance at Instituto de Medicina Integral Prof. Fernando Figueira, 2009.

\begin{tabular}{|c|c|c|c|c|c|}
\hline Variables & PTN & FTN & Total & $\mathrm{PR}(\mathrm{Cl})$ & $p$ \\
\hline & $n(\%)$ & $n(\%)$ & $n(\%)$ & & \\
\hline Age (Years) & & & & & $0.685^{\circ}$ \\
\hline$<18$ & $7(53.8)$ & $6(46.2)$ & $13(100)$ & 1.00 & \\
\hline $18-35$ & $37(50.7)$ & $36(49.3)$ & $73(100)$ & $1.06(0.61-1.84)$ & \\
\hline$>35$ & $2(33.3)$ & $4(66.7)$ & $06(100)$ & $1.62(0.47-5.57)$ & \\
\hline Schooling (years) & & & & & $0.707^{\prime}$ \\
\hline$<4$ & $03(50.0)$ & $03(50.0)$ & $06(100)$ & 1.00 & \\
\hline 4 to 8 & $09(42.9)$ & $12(57.1)$ & $21(100)$ & $1.17(0.46-2.99)$ & \\
\hline$>8$ & $31(53.4)$ & $27(46.6)$ & $58(100)$ & $0.94(0.41-2.16)$ & \\
\hline Income & & & & & $0.241^{\prime}$ \\
\hline$<1$ & $8(44.4)$ & $10(55.6)$ & $18(100)$ & 1.00 & \\
\hline$>1$ & $38(51.3)$ & $36(48.7)$ & $74(100)$ & $0.87(0.49-1.52)$ & \\
\hline Delivery type & & & & & $0.325^{\circ}$ \\
\hline Normal childbirth & $21(53.8)$ & $18(46.2)$ & $39(100)$ & 1.00 & \\
\hline Surgical childbirth & $25(49.0)$ & $26(51.0)$ & $51(100)$ & $1.10(0.73-1.64)$ & \\
\hline Forceps childbirth & $00(0.0)$ & $02(100.0)$ & $02(100)$ & $0.00(0.00-0.00)$ & \\
\hline Prenatal care (n) & & & & & 0.024 \\
\hline 0 & 03 & 01 & $04(100)$ & 1.00 & \\
\hline 1 to 5 & 26 & 16 & $42(100)$ & $1.21(0.66-2.24)$ & \\
\hline$>5$ & 14 & 27 & $41(100)$ & $2.20(1.08-4.46)$ & \\
\hline
\end{tabular}

*Exact Fisher test; PTN=preterm newborn; FTN=fullterm newborn; $\mathrm{n}=$ absolute frequence; \%=relative frequence; $\mathrm{PR}=$ prevalence ratio; $\mathrm{Cl}=$ confidence interval.

Table 2. Raw-score and classification of motor development of preterm infants at equivalent age and fullterm newborn as the Test of Infant Motor Performance, at Instituto de Medicina Integral Prof. Fernando Figueira, 2009.

\begin{tabular}{lcccc}
\hline & & PTN & FTN & $p$ \\
Raw-Score $($ mean \pm SD) & & $58.0 \pm 7.9$ & $67,9 \pm 5.3$ & $p<0.001^{*}$ \\
\hline \multirow{3}{*}{ Motor development } & Tipical n (\%) & $34(73.9)$ & $46(100.0)$ & \multirow{2}{*}{$p<0.001^{* *}$} \\
\cline { 2 - 4 } & Atipical n (\%) & $12(26.1)$ & $0(0.0)$ & \\
\cline { 2 - 4 } & Total n (\%) & $46(100.0)$ & $46(100.0)$ & \\
\hline
\end{tabular}

* Student's t-test; ** Exact Fisher test; SD=Standard deviation; n=absolute frequence; \%=relative frequence; PTN=preterm newborn; FTN=fullterm newborn. 
Table 3. Raw-score and classification of motor development at preterm infants with or with or without intercurrences* according to the Test of Infant Motor Performance, 2009.

\begin{tabular}{|c|c|c|c|c|}
\hline & & With intercurrences ${ }^{*}(n=18)$ & $\begin{array}{l}\text { Without intercurrences * } \\
\qquad(\mathrm{n}=28)\end{array}$ & $p$ \\
\hline Raw-score (mean $\pm S D$ & & $56.39 \pm 6.51$ & $59.07 \pm 8.79$ & $p<0.246^{\star *}$ \\
\hline \multirow{3}{*}{ Motor development } & Tipical n (\%) & $15(83.3)$ & $18(66.7)$ & \multirow{3}{*}{$p<0.308^{* \star *}$} \\
\hline & Atípical n (\%) & $3(16.7)$ & $9(33.3)$ & \\
\hline & Total n (\%) & $18(100.0)$ & $27(100.0)$ & \\
\hline
\end{tabular}

$\mathrm{SD}=$ Standard deviation; $\mathrm{n=absolute}$ frequence; \%=relative frequence; PTN=preterm newborn; FTN=fullterm newborn; * intercurrences: slight infections, persistent ductus arteriosus and/or intracranial hemorrhage grade I or II; ** Student's t-test; ${ }^{\star \star \star}$ Exact Fisher test.

\section{Discussion $: \because$.}

The results of the TIMP assessment revealed that preterm newborns present, at an equivalent age, poorer motor performance than full-term newborns, both in raw score and in classification as typical or atypical. These findings are similar to those of other authors investigating preterm newborns similar in age to the sample in this study ${ }^{24,10}$. One of these studies ${ }^{24}$ used specially-developed software to assess motor response in preterm and full-term newborns and compared video of four items tested in both groups (PTN and FTN at the same age), verifying that the preterm newborns had poorer motor performance than the full-term newborns. Another study ${ }^{10}$ using a goniometer to assess muscular tone showed that it was lower in preterm than in full-term newborns. Mercuri et al. ${ }^{25}$, using a neonatal behavioral examination, found that the preterm newborns had lower flexor tone in the limbs and extensor tone in the neck than full-term newborns. The fact that these studies, although methodologically different, found motor insufficiencies in premature newborns supports the evidence that the preterm newborns, even when reaching term age, still present poorer motor performance than the full-term newborns.

It is important to point out that the differences found in the present study are not due to maternal characteristics, since they did not differ between the groups, except regarding the number of prenatal consultations, but this comparison is not informative because the infants were born at a lower gestational age.

On the other hand, differing from the present study, several authors have found an association between gestational age ${ }^{31,32}$ or birthweight ${ }^{31,32}$ or a longer stay in the hospital after birth ${ }^{31}$ and risk factors for delayed motor development. This difference, in comparison to our results, could be explained by the use of different criteria to determine associations. In fact, the purpose of the correlations found in this study was to determine the association between the size of the absolute values of the raw score with the size of the infants' exposure factors, while other studies have investigated the relationship between dichotomous outcomes (presence or absence) with exposure factors. Since no relationships were found between raw score and any of these factors in isolation, it is possible that the effect observed in the premature babies was due to a synergistic interaction between the exposure factors.

A fundamental difference between the two groups compared in this study was the environment to which they were exposed in the weeks that preceded the TIMP assessment. Preterm newborns were exposed to the environments of the NICU and NIC, the Kangaroo Unit or even their home while the FTN group remained in the intrauterine environment. There is evidence that the high noise level, intense luminosity, lack of day/night cycles and excessive handling in the NICU and NIC environments might damage preterm infant development ${ }^{8}$, whereas intrauterine environmental factors might facilitate development ${ }^{9}$. Therefore, since the age of preterm infants was corrected to equal that of the FTN group, the observed differences could have been due to the reduced stay in intrauterine environment and to inundation with stress factors in the NICU during a period of insufficient neurological maturity.

The fact that PTN weight was not measured on the TIPM evaluation day can be counted among the limitations of the present study, since it precluded verification of any association between weight and the raw TIMP score. Another limitation that might have caused a bias is the fact that the losses in the PTN group were all newborns who had already been discharged on the TIMP assessment day. However, variation in time since discharge showed no association with the outcome.

In summary, the findings of this study support previous results that prematurity has a negative influence on motor performance, putting the preterm infant at a disadvantage when compared to the full term infant, and that the TIMP is valuable for investigating motor development in premature newborns who are studied at term age. In addition, this is the first study, to our knowledge, using the TIMP to compare newborns in this age group. Longitudinal studies would be relevant for investigating whether the differences found in this study persist over time, as well as whether the observed differences carry over into the posterior neuropsychological development of these infants. Interventional studies verifying the efficacy of appropriate stimulation programs would be of equal importance. 
References : :

1. Stephens BE, Vohr BR. Neurodevelopmental outcome of the premature infant. Pediatr Clin North Am. 2009;56(3):631-46.

2. Arpino C, Compagnone E, Montanaro ML, Cacciatore D, De Luca A, Cerulli A, et al. Preterm birth and neurodevelopmental outcome: a review. Childs Nerv Syst. 2010;26(9):1139-49.

3. Barbosa VC, Formiga CKMR, Linhares MBM. Avaliação das variáveis clínicas e neurocomportamentais de recém-nascidos pré-termo. Rev Bras Fisioter. 2007;11(4):275-81.

4. Bonvivine C, Quibão EF, Asa SKP, Silva PN, Gaetan ESM. Prematuridade como possível fator influenciador do controle de cabeça. Salusvita. 2004;23(3):489-512.

5. Pereira MR, Funayama CAR. Avaliação de alguns aspectos da aquisição da linguagem de crianças nascidas pré-termo. Arq Neuropsiquiatr. 2004;62(3A):641-8.

6. Rodrigues MCC, Mello RR, Fonseca SC. Learning difficulties in schoolchildren born with very low birth weight. J Pedriatr. 2006;82(1):6-14.

7. Magalhães LC, Catarina PW, Barbosa VM, Mancini MC, Paixão ML. Estudo comparativo sobre 0 desempenho perceptual e motor na idade escolar em crianças nascidas pré-termo e a termo. Arq Neuropsiquiatr. 2003;61(2A):250-5.

8. Vanderveen JA, Bassler D, Robertson CM, Kirpalani $\mathrm{H}$. Early interventions involving parents to improve neurodevelopmental outcomes of premature infants: a meta-analysis. J Perinatol. 2009;29(5):343-51

9. Aucott S, Donohue PK, Atkins E, Allen MC. Neurodevelopmental Care in the NICU. Ment Retard Dev Disabil Res Rev. 2002;8(4):298-308

10. Da Silva ES, Nunes ML. The influence of gestational age and birth weight in the clinical assesment of the muscle tone of healthy term and preterm newborns. Arq Neuropsiquiatr. 2005;63(4):956-62.

11. Sweeney JK, Gutierrez T. Musculoskeletal implications of preterm infant positioning in the NICU. J Perinat Neonatal Nurs. 2002;16(1):58-70.

12. Georgieff MK, Bernbaum JC, Hoffman-Williamson M, Daft A. Abnormal truncal muscle tone as a useful early marker for developmental delay in low birth weight infants. Pediatrics. 1986;77(5):659-63.

13. Georgieff MK, Bernbaum JC. Abnormal shouder girdle muscle tone in premature infants during their first 18 months of life. Pediatrics. 1986;77(5):664-9.

14. Vaivre-Douret L, Ennouri K, Jrad I, Garrec C, Papiernik E. Effect of positioning on the incidence of abnormalities of muscle tone in low-risk, preterm infants. Eur J Paediatr Neurol. 2004;8(1):21-34.

15. Blauw-Hospers $\mathrm{CH}$, Hadders-Algra M. A systematic review of the effects of early intervention on motor development. Dev Med Child Neurol. 2005;47(6):421-32.

16. Assaiante C, Mallau S, Viel S, Jover M, Schmitz C. Development of postural control in healthy children: a functional approach. Neural Plast. 2005;12(2-3):109-18

17. Campbell SK, Kolobe TH, Osten ET, Lenke M, Girolami GL. Construct validity of the test of infan motor performance. Phys Ther. 1995;75(7):585-96.

18. Rose RU, Westcott SL. Responsiveness of the Test of Infant Motor Performance (TIMP) in infants born preterm. Pediatr Phys Ther. 2005;17(3):219-24.

19. Campbell SK, Kolobe TH, Wright BD, Linacre JM. Validity of the Test of Infant Motor Performance for prediction of 6-, 9- and 12-month scores on the Alberta Infant Motor Scale. Dev Med Child Neurol. 2002;44(4):263-72.

20. Darrah J, Piper M, Watt MJ. Assessment of gross motor skills of at-risk infants: predictive validity of the Alberta Infant Motor Scale. Dev Med Child Neurol. 1998;40(7):485-91.

21. Miller LJ, Roid RG. The T.I.M.E: Toddler and infant motor evaluation: a standardized assessment. Tucson: therapy Skyll Builders; 1994.

22. van Hartingsveldt MJ, Cup EH, Oostendorp RA. Reliability and validity of the fine motor scale of the Peabody Developmental Motor Scales-2. Occup Ther Int. 2005:12(1):1-13

23. Bayley N. Bayleys scales of infant and toddler development ${ }^{\circledR}$ (Bayley III ${ }^{\circledR}$ ). $3^{\text {rd }}$ ed. San Antonio: Harcourt Assessment, Inc.; 2005.

24. Cameron EC, Maehle V. Comparison of Active Motor Items in Infants Born Preterm and Infants Born Full Term. Pediatr Phys Ther. 2006;18(3):197-203.

25. Mercuri E, Guzzetta A, Laroche S, Ricci D, vanhaastert I, Simpson A, et al. Neurologic Examination Of Preterm Infants At Term Age: Comparison With Term Infants. J Pediatr. 2003;142(6):647-55.

26. Lekskulchai $\mathrm{R}$, Cole J. Effect of a developmental on motor performance in infants born preterm. Aust J Physiother. 2001;47(3):169-76.

27. Campbell SK, Levy P, Laura Zawacki L, Liao PJ. Population-based age standards for interpreting results on the Test of Motor Infant Performance. Pediatr Phys Ther. 2006;18(2):119-25.

28. Dados do SINASC - IMIP. Disponível na coordenação da neonatologia do IMIP. 2008.

29. Campbel SK. The Test $f$ Infant Motor Performance. Test User's Manual Version 2.0. Chicago: 2005

30. Barbosa VM, Campbell SK, Sheftel D, Slingh J, Beligere N. Longitudinal performance on infants with cerebral palsy on the Test of Infant Motor Performance and on the Alberta Infant Motor Scale. Phy Occup Ther Pediatr. 2003;23(3):7-29.

31. Skrablin S, Maurac I, Banović V, Bosnjak-Nadj K. Perinatal factors associated with the neurologic impairment of children born preterm. Int J Gynaecol Obstet. 2008;102(1):12-8.

32. Formiga CKMR, Linhares MBM. Detecção de risco para problemas no desenvolvimento de bebês nascidos pré-termo no primeiro ano [tese]. Ribeirão Preto: Faculdade de Medicina de Ribeirão Preto/USP; 2009. 